\title{
PERFORMANCE OF SHORT AND LONG RANGE WIRELESS COMMUNICATION TECHNOLOGIES IN CONSTRUCTION
}

\author{
Payam R. Zekavat ${ }^{1}$, Sungkon Moon ${ }^{1}$, and Leonhard E. Bernold ${ }^{2}$ \\ ${ }^{1}$ PhD Candidate, School of Civil and Environmental Eng., UNSW, Kensington, NSW, \\ Australia \\ ${ }^{2}$ A/Professor, Department of Civil Engineering, Universidad Tecnica Federico Santa Maria, \\ Valparaiso, Chile
}

\begin{abstract}
The ever increasing complexity of construction projects asks for improved communication and automated data collection supported by continually improving electronic tools. Advances in information technologies enable us to link critical resources on construction sites, such as trucks and cranes, to the project website creating many opportunities to drastically improve productivity, safety and quality. While the use of electronic equipment is nothing new in construction, no model exists to integrate them into one unified framework. This paper presents a wireless site-network concept consisting of information hubs enabled to automatically connect data sinks with sources supported by software agents. Included in this paper is the discussion of a mobile information hub, the $e$ CKiosk, enabled to connect the work crew electronically to the project network while collecting automatically live "as-built" data. It begins with a review of long range wireless as the basis for designing a robust Agile Site Communication Network (ASCNet). Site experiments with short range wireless conduits and embedded RFID tags showed that they are able to provide information far beyond an identification number. While wireless technologies are poised to open totally new avenues to manage construction, more field-tests are needed to establish a solid knowledge base to create a pervasive network for the dynamically changing building site.
\end{abstract}

Keywords: Agile Site Communication Network; eCKiosk; Work-front Information Flow; Wireless Signal Coverage Range; RFID.

\section{Introduction}

Reports and papers continue to highlight the effect of poor communication in construction. It's felt that the "nerve system" of management on construction site is slow and 
its reach limited while lacking suitable communication media [1]. The long overdue adoption of the Building Information Modelling (BIM) standards advances only slowly into the actual construction where the high cost of poor interoperability between design and construction software still remains [2]. One critical area of weak communication is the "space" between the already networked main office and the work-front. According to Nuntasunti and Bernold [3] "the digital format of wireless communication opens the possibilities to link sensors and devices that are mounted on the equipment, machines, and tools to the integrated wireless site (IWS). "

Despite the rapid developments in wireless technology designed for high performance in rough environments the manual paper-based dissemination of drawings, work and change orders is still the state-of-the-practice in construction. In particular, wireless devices utilizing the IEEE $802.11 \mathrm{~b}$ and g protocols are "robust" enough to link the many construction work crews, electronic sensors and other devices in real time to the Project Communication Network (PCN) presently mainly used by designers and upper level project managers. Illustrations of recent developments include: a) WiFi, b) ZigBee, c) Wireless Sensor Network (WSN), d) Radio Frequency Identification (RFID), e) sensor-equipped construction equipment, f) global data standards and high transfer rates up to 600Mbps from IEEE 802.11n. One example of a ruggedized equipment data acquisition system utilized in construction is the Measurement While Drilling (MWD) that integrates several sensors (i.e. accelerometer, magnetometer, temperature, vibration) applying a telemetric communication system [4]. Real time measurements from drill bit are continuously communicated to the surface in support of steering resulting in faster, safer and more accurate drilling. With the provided data, the operator is able to monitor the performance of all important components of the machine on a high resolution monitor screen. In addition drilling data are collected to create live "as-builts" related to the sub-surface. Still the MWD's feedback data is not shared. Connecting this 
"island of information" to other equipment or to the PCN, however, requires the hurdling of several obstacles; a) Integration of communication hardware, b) providing power, c) interoperability between systems, d) data security, e) ownership of data, f) user-friendliness, g) cost, and h) ruggedized housing against dust, heat and rain.

The construction supply chain is another area that has applied wireless technologies. Many suppliers take advantage of RFID and GPS on a regular basis to locate their resources. So far, their use is limited to tracking containers, trucks and pieces of material. This leaves many opportunities to reduce present process wastes such as resource idleness, time for rehandling and searching for missing material which are mainly caused by poor supply control. In order to create a seamlessly integrated monitoring network covering the entire supply chain, it is necessary to improve our understanding the performance of wireless devices and their electromagnetic transmissions on construction sites. For example, Tzeng et al. [5] pointed out that distance, relative angle, location and response time are the most critical factors in determining RFID tag's readability rate, vital to its successful use in construction.

This paper will discuss the results of field testing several wireless methods after introducing a site communication network capable of linking mobile information hubs to the PCN.

\section{An Agile Site Communication Network (ASCNet)}

Most construction sites receive their resources by road transport. To plan a most efficient unloading process the exact arrival time, the size of the vehicle and its load has to be available. At present, such upfront data is not readily obtainable as the various sources are still operating as "islands of information". Figure 1 offers a model designed to create communication links between essential data sources and sinks, constituting a smart construction site [6-8]. In the demonstrated hypothetical situation, the ASCNet includes the main resources involved in 
placing concrete for a slab such as GPS embedded concrete supply trucks, concrete pump and a tower crane. Although the GPS data is used by suppliers to manage their hauling fleets, the tracking data would be invaluable information to the site. For instance, projected arrival times of the supply trucks could be instrumental in managing the placement crew thus minimizing idleness of both truck and crew. The essential enabling tool is the use of a mobile electronic information hub as a reliable access point for various devices.

Each work crew is assigned its own hub, in operating similar to a mobile-phone, linking the work-front to the PCN. Figure 1 indicates that a wireless access point (WAP) provides the coverage with radio signals using one of the $2.4 \mathrm{GHz}$ IEEE 802.11 protocols. Of course, the constantly changing construction site and the moving equipment create many interferences leading to electronic noise and, as a result, to abrupt signal loss. Hence, the design of a reliable WiFi network depends on a deep understanding of potential attenuations that need to be compensated by installing signal repeaters in a proactive manner.

[Figure 1]

Figure 2 shows the new communication hub interfaced with other modules and the ASCNet and a wireless sensor network that facilitates data acquisition for automatic documentation. At the same time, sensors embedded in the operation are able to collect data of critical measures (e.g., pressure) about the work in progress and, supported by software agents, sound the alarm about unsafe developments or delays on the supply route. If designed effectively, the communication hub serves as a proactive feed-forward control to avoid costly process wastes and unacceptable output quality.

[Figure 2]

Interoperability of the selected tools consisting data hubs able to provide, collect and transceive data, RFID readers, electronic sensors, cameras, and etc. is essential in order to supply key information in the recognized complex communication pattern. In summary, the 
smart site is functional only if different pieces of hardware are compatible to secure required wireless conduits. The remaining part of the paper will discuss the pretesting of physical and communication layers followed by the outcome of field-tests.

\section{Pretesting of System Components}

The main challenge in establishing a strong wireless backbone to support mobile information hubs is the creation of a reliable communication network providing sufficient signal coverage throughout the entire site. As mentioned earlier, the dynamics of a construction site threatens the availability of signal strength at critical spots. Of course, utilization of embedded RF tags brings in different difficulties as the RF signals interact with fresh concrete with high water content, hardened concrete as well as steel reinforcing bars. Following section introduces the prototyped information hub followed by the results of systematic studies on the performance of each wireless technology.

\subsection{The Electronic Construction Kiosk (eCKiosk)}

As was outlined above, one keystone of a functioning ASCNet is the mobile information hub capable of real time multi-directional communication and automated data acquisition. Based on this architecture an electronic Construction Kiosk (eCKiosk) was designed, built and tested. The requirements and constraints of an active construction site required a sturdy structure flexible enough not only to easily relocate on the site but also to adapt its communication interfaces. Different than the $i$ booth presented by Ruwanpura et al. [9] the technology reaches beyond the safety of the site office. Similar to the telemetric digital workbench [10], the latest design of the $i$ booth presented in [11] lacks the agility to address the information needs at the point of work. What makes $e$ CKisok an information hub, rather than a simple information board, is its mobility and its bi-directional communication. 


\subsubsection{Design of a Human-Computer-Interaction (HCI) for Work Crews}

Dzeng et al. [12] suggested taking advantage of smartphones on site for applications such as detecting fall portents with the built-in accelerometer. On the other hand, the site use of smartphone, for communication beyond talking, is limited due to its small screen and the harsh construction environment. In fact, the use of smartphones is only recommended for delivering brief oral reports to the site manager [13].

The design of a HCI for construction has not only to consider the harsh environment but, equally important, the information needs, ease-of-use and minimization of work interruptions. Figure 3 presents the $e$ CKiosk prototype, consisting of a steel structure supporting a tarp cover to protect against sun, wind, rain, and dust. Its lifting lugs and the rugged casters provide the needed mobility to follow the crew. However, most important are the set of devices that are built into the kiosk and the nature of information exchange they support. Most prominent is the large touchscreen with several easy to understand data-windows. Naturally, the screen size has been selected to allow several workers to view it simultaneously while quickly finding details using the touch screen. Also shown are the expandable worktable as well as the various data collection technologies such as the wireless ZigBee data logger, video camera, microphone and loudspeakers. With the present set of devices, which can be easily expanded, a set of interesting capabilities are being enabled: 1) Access to up-to-date electronic information, 2) audio-video chat, 3 ) text-to-speech broadcast of critical communication, 4) supply truck GPS tracking, 5) automatic/direct interaction with WiFi embedded equipment on site, 6) voice-based/hands-free messaging and documentation, and 7) collection of wireless sensor data (i.e., temperature, wind, humidity).

[Figure 3]

\subsubsection{Data Overload Prevention and Security}


The capabilities of collecting real-time data from an active construction will open a long list of benefits for improving its performance easily leading to data overload and creating new security risk in the system. The $e$ CKiosk design provides the opportunity to employ software agents that screen the data flow at its source. Many authors such as Lee and Bernold [14] have shown that such software agents are able to autonomously monitor and process large volumes of data reducing the overload risk. Agents can also protect communication networks against malicious intruders or send out warnings. Furthermore, a virtual "security ring" is able to inspect all communications and transactions among participants passing through [15]. Furthermore, Firewalls, Intrusion Detection Systems (IDS) and antivirus protection software protect each individual information user (node).

The following section of this paper will discuss results from field-testing two common wireless network modes, WiFi and ZigBee. Each occupies a band of frequencies around 2.4 $\mathrm{GHz}$, some of which overlap. On the other hand, they follow different communication protocols: WiFi uses IEEE802.11b and ZigBee IEEE801.15.4. Figure 1 highlighted that the two networks share the same space on a construction site which may result in interferences, blocking or delaying communication because of the intermittent loss of RF packets. What adds to the complexity is the nature of constructing a building which may require a constant modification to ensure connectedness throughout the site. No data about the combined effect of "frequency sharing", growth of a building structure made of various materials, and moving construction equipment on the performance of RF signals exists. For this reason a set of onsite experiments were designed, executed and are documented here.

\subsection{The Quest to Provide Sufficient Signal Coverage}

The performance of a wireless system is closely linked to the deterioration rate of the wave energy between the transmitter and the receiver referred as signal attenuation. In turn, 
the rate is a function of electromagnetic properties of the media, electromagnetic noise, as well as the geometry and material characteristics of obstacles to the RF signals. Although WiFi and ZigBee signal share some frequencies around $2.4 \mathrm{GHz}$, the differences in IEEE standards result in dissimilar features in terms of network topology, data rate, power consumption, and number of access nodes. Finally, data security has to be considered adding to the complexity for the network design.

Before discussing the design and results of field-tests to measure signal quality behavior on a selected construction site, a quick review of principles related to signal attenuation is provided.

\subsubsection{Signal Attenuation}

Electromagnetic signals are emitted with a predefined amount of energy or power intensity that dissipates into the 3-D space as a function of an antenna's power gain. Objects that obstruct the linear paths cause losses through absorption by surrounding media or scattering at edges or uneven surfaces. Absorption losses, measured in decibel (dB), can be calculated based on the known characteristics of the material such as those presented in Table 1.

[Table 1]

In addition, signals that "hit" a denser material in a non-vertical angle get reflected and diverted from the line-of-sight path. The latter phenomenon regulates the coverage map particularly where the surface of the target area is subject to change. Construction site features are continuously changing making it difficult to cover the entire site wirelessly during the life of a project. Even during a workshift the conditions are subject to change. Moving equipment affect network performance by blocking line-of-sight between transmitter and receiver. The first set of measurements was designed to assess the interferences of 
materials that are temporarily stored, such as piles of excavated soil, combined with electric noise from motors on operating equipment, such as backhoes and trucks. It is hypothesized that due to the irregular current flow or the changing of gears in a rotating electric motor, the RF signals will be interrupted decreasing the signal-to-noise-ratio and hence leading to an increase in the number of erroneous messages.

\subsubsection{WiFi Network Performance Test}

Dong et al. [16] discussed the problem with effective coverage of WiFi networks as the main barrier toward successful implantation of the IEEE 802.11 technology. They also mentioned signal jamming and interference with other radio signals from the same frequency category as secondary hindrance of proper functioning of WiFi networks. In the view of these traits the performance of wireless network in the construction environment is under question. Simulating the real world of a construction site to study the behavior of RF signals is extremely difficult necessitating equipment tests in the "messy" environment. For this reason, a series of on-site measurements on a live construction site were planned.

A multistory student accommodation complex on the campus of UNSW served as a testfacility to collect data about the behavior of RF signals over time. The site was surveyed for the first time on 01/09/2012. As depicted in Figure 4, the project consisted of three building blocks, A, B and C. In September of 2012, foundation work for Block B and Block C was in the process of being completed. As indicated, a last section of 3 meter deep sandy soil was left to be excavated and removed by dump trucks. The area covered by the initial signal strength survey was $120 \mathrm{~m}$ long and $40 \mathrm{~m}$ wide surrounding Block B and Block C as well as the area in between. Figure 4 also indicates the location of the origin $(0,0)$. The width was divided into four 10 meter wide strips, with the vertical borderlines $1,2,3,4,5$, and the 
length into five sections between the horizontal lines A to F. Signal strength measurements were made at the intersections of the two reference lines.

[Figure 4]

Figure 5 presents the 3-Axis RF Field Strength Meter (TM-195) used to measure the RF power intensity in $\mu \mathrm{W} / \mathrm{cm}^{2}$. To compensate for the sensitivity of the field sensor in the 2.4 $\mathrm{GHz}$ range, the calibration factor was set to 0.66 . The collected data was uploaded to Matlab which allowed the creation of the electromagnetic power density contour maps displayed in Figure 6-a) from the first survey on 01/09/2012. For convenience, the RF power densities are reported in $10^{1} \mu \mathrm{W} / \mathrm{m}^{2}$. The curves perpendicular to the contours indicate the related signal paths. Propagation occurs along the paths from a contour with a higher towards a smaller density contour. The closer the contours are, the higher is the signal attenuation along that path. For example, the highlighted area enclosed by the contour of $20 \times 10^{1} \mu \mathrm{W} / \mathrm{m}^{2}$ illustrates the area with highest probability of lost signal. The change in the area of this region is an indicator of the signal's behavior interacting with construction elements such as the excavation pit. The topology of the sloped pit face as well as access ramp is shown at the bottom-right hand side of the foundation. Note that in Figure 6-a) the measurements at points $(5, A),(5, B)$ and $(5, C)$ were made while standing on the top of the excavation. On 24/09/2012, the excavation was almost complete and the soil piles were flattened to provide a $4 \mathrm{~m}$ wide access road. The centreline of the road coincided with the right edge of the surveyed area. The $90 \times 10^{1} \mu \mathrm{W} / \mathrm{m}^{2}$ peak from the first test, shown in Figure 6-a), resulted in the accumulation of diffracted signals hitting the sharp edges of sand grains scattering and blocking their paths. By back-tracking the shown contours toward the highest intensity one can detect two signal transmitter locations. The stronger omni-directional one is located at right hand side and the weaker directional antenna on the top. In fact, the two antennas were located closely to the perimeter of the construction site (on adjacent buildings) operated by 
the University WiFi network (UniWide). Identified antennas were considered the only external source of emission to create the base background map. Knowing the base background signal level, any altered changes can be tracked by subtracting base pattern from existing situation. In addition, signal propagation can be studied accurately by installing a transmitter in the site and measuring the propagation mode when all other effects from external radiation sources are determined. Figure 6-b) illustrates the second measurement at the foundation level. Removing the soil provided line-of-sight for the signal into the bottom half of Block B and clearly provides more uniform and smoother signal variation at the center of foundation pit. Actually, the second graph magnifies the significance of the WiFi antenna on the right hand side of the site in establishing a reliable coverage. Furthermore, penetration of the directional antenna has also been doubled. However, its location might have been slightly adjusted as the directions between the two readings changed. Indeed, the fraction of emitted power wasted because of backscattering is now used to penetrate further into 3-D space.

[Figure 5]

[Figure 6]

\subsubsection{Testing Link Interferences of Power Cable and Radio}

The recommended dedicated service, for a $260 \mathrm{hp}$ crane manufactured by Terex is 300 amps (480V). While every crane has slightly different power requirements a detailed study by [17] approximates these values. The paper lists the electricity cost for the 10 months use of a tower crane for the construction of a seven story building at Texas A\&M University as \$ 140,000 . Assuming a rate of 6.81 cents per $\mathrm{kWh}$ (for 2002), a $50 \%$ standby factor, and an 8 hours workday, the average power consumption of the motors amount to $257 \mathrm{hp}$ drawing a maximum of 305 amps (480V). Two field-tests around a fixed Liebherr saddle-jib tower 
crane were conducted to determine potential impacts of electric power cable and a hand-held radio on the quality of ZigBee links. The $280 \mathrm{EC}-\mathrm{H}$ 's manual doesn't provide service power data but has a $110 \mathrm{~kW}$ hoisting winch and three $7.5 \mathrm{~kW}$ drive units for slewing and trolley travel. Therefore, crane's power cable is estimated to carry approximately 190 amps (480 V) generating a cylindrical magnetic field of $0.38 \mathrm{G}$ at a radius of one meter. The crane's operational state as well as the distance were considered important factors. Furthermore, because the power cable ran vertically along the outside of tower's truss sections the angular orientation of the "nuisance ray" emitted by the EM field of the cable was also included as the third factor. Per se, the tower sections themselves were hypothesized to agitate the propagation pattern of EM radiation. A full factorial experiment with three replications was designed using proper statistical software. Two levels defined for crane status included "under power" and idle that corresponds to value levels of +1 and -1 in the design. The crane was considered active only when it was hoisting a load heavier than one tonne. An idle value refers to situation where the operator is not in the cabin. The electromagnetic field around a cable decays inversely with the radius leading to the consideration of two measurement points at one and five meters. As shown in Figure 7-a), the test set-up used three spatial axes to define the links between a central data logger fixed beside the power cable and a mobile sender moved around the crane. Table 2 displays the matrix of measurements. A general linear regression model for all main effects and two-way interactions was fitted to the sample data. The mean-sum-of-squares for the model and error are 75.8 and 104.3 correspondingly which lead to F-test statistic 0.73 with P-value 0.63 . Based on this result, even at a significance level of 0.10 , the P-value associated to F-test is not small enough to indicate that even one of the factors is important. It was expected that sudden draw of the current when the operator changes the gear would cause sharp peaks in EM radiation. However, the lack of such spikes indicates that the crane was equipped with a soft-starter that flattens the large 
startup inrush current associated with the large hoist motor. Indeed, the regression model shows that EM radiation of the cable causes no relevant decay in signal strength beyond a radius of one meter. Therefore, the collected data should be a set of observations drawn at random from a normal distribution with mean 70.1 and standard deviation 10.0. However, the normal probability plot of link quality has a P-value of 0.47 which doesn't support the normality of data. A look at the regression model shows that although the linear regression model is not best fit to the data, with P-value of 0.14 , the crane status has the lowest $\mathrm{P}$-value among all the factors. This suggests that EM fields from other sources are interfering thus causing the data to deviate from a normal distribution. One apparent secondary source are the handheld radios that are always used during a lift. In fact, an inspection of the two-way radios proved that they are operating in the same frequency range as ZigBee. To investigate this source of "noise", link quality data was collected at random points around the tower when the two-way radio was on and off. Figure 7-b) shows the site foreman holding the portable node at a random spot during the second test. Note that crane is not excluded from the second set of tests. Typically, when radio is used the crane is "under power" that means any potential effect is a result of combination of both EM fields from power cable and radio. Each pair of measurements was done under equal conditions. The results of these second tests are presented in Table 3. The paired t-test highlights the difference in mean link quality between the two possible statuses $\left(\mu_{D}=\mu_{\text {idle }}-\mu_{\text {active }}\right)$. The null hypothesis $\mathrm{H}_{\mathrm{o}}: \mu_{\mathrm{D}}=0$ is tested against alternative hypothesis $\mathrm{H}_{1}: \mu_{\mathrm{D}}>0$. The P-value for the test statistic of $t_{0}=2.73$ is 0.006 . Therefore, it can be concluded that the use of two-way radios adversely affected signals by lowering the Link Quality Index (LQI) for 8.6 units. In summary, the two tests confirm that the combined effects of EM radiation generated by two-way radios and the main power cable do interfere with the RF signals of ZigBee and possibly WiFi and their negative effects need to be considered in designing a wireless network. 
[Table 2]

[Table 3]

\subsection{Embedded RFID to Track Objects in ASCNet}

By advancing of the information delivery tools and methods, several valuable applications are extended to answer real-time information need of mobile workers. One area is establishing direct link between RFID tags and central project management server/database to automatically update building product and work progress data. Updated progress report enhances the efficiency of project control. While its operation doesn't require line of sight it can be encapsulated to survive in construction harsh environment. RFID is a data source in ASCNet and different users benefit from it in different ways. Radiated RF signal from RFID reader stimulates the tag and the stored information is communicated with the reader in the form of electromagnetic field. As part of a wireless network its capability to link to whole system needs to be examined.

\subsubsection{Performance of RFID Tags Embedded in Concrete}

To test the feasibility of proposed back-tracking of concrete elements, sets of preliminary tests were conducted in the laboratory to examine readability and survivability of RF tags inside the concrete. A RFID tag, encapsulated in cylindrical plastic protector, was used in the experiments. The selected tag has an operating frequency range of $902 \mathrm{MHz}-928 \mathrm{MHz}$ which is classified as ultra high frequency with recommended application for logistics [18]. Although, automated monitoring and control of field information lead to more efficient construction practice, several challenges need to be overcome [19]. To understand the concrete-RF interaction in detection mechanism a simple comparison was done. The preliminary experimental setup is presented in Figure 8. Because passive tags were used, the 
reader is the only emission source. The transmitted signals should have certain amount of energy to travel form transmitter to concrete surface, penetrate into the concrete, activate the tag, initiate a response signal and the excited signal must return all the way back to the reader antenna. A radio strength meter, fixed at the spot, recorded the signal power in its vicinity as the RFID reader moved away. Three different setups refer to position a) Nothing, b) only a tag, or c) a concrete cylinder with an embedded tag, close to signal meter. Results of measurements depicted in Figure 9 show that performance of the RFID tag is affected by the concrete. Note that the vertical axis in Figure 9 is in logarithmic scale. Observations confirm that the selected tag can survive inside the concrete and communicate with the reader. The first observation was that the probability of the successful detections increased by the age of fresh concrete. Although fresh concrete absorbs transmitted electronic signals from reader, after curing embedded tag was easily detectable inside the concrete sample which was quite compatible with other observations [20-21]. Another interesting phenomenon was that concrete cylinder magnified the detection range which is interpreted as the effect of concrete cylinder in concentrating the signals. Indeed, concrete cylinder works as an antenna to gain more energy and empower the transmitted response. This is why the detection range is almost three times greater than what achieved in tag only case. The same phenomenon is predicted if the tag placed in a concrete beam or column. In order to systematically investigate tagconcrete interaction in more detail, the measurements for the last two setups were replicated ten times in random orders. The outcomes reported in Table 4 are used to perform a twosample T-test to test the null hypothesis of equal sample means against the alternative hypothesis of $\mu_{1}<\mu_{2}$. Indeed, because the calculated standard deviations of two samples don't support the assumption of equal variances, an exact t-statistic doesn't exist for the test. However, it's reasonable to assume that a statistic defined by Equation 1 has approximately tdistribution with 12 degrees of freedom. 
$t_{o}^{*}=\frac{\bar{x}_{1}-\bar{x}_{2}}{\sqrt{\frac{s_{1}^{2}}{10}+\frac{s_{2}^{2}}{10}}}=-21.4$

Because $\mathrm{t}_{0.005,12}=4.318$ and $\left|t_{o}^{*}\right|=21.4$, we find that $\mathrm{P}$-value for the test is less than 0.005 so we reject the null hypothesis and conclude that the detection range for the tag in the concrete cylinder is larger than the tag alone. However more investigation is required to figure out the exact response in real world when the tag is placed in concrete slab.

Another important factor that hypothesized to impact the detection range of the embedded RFID tags is the rebar. In fact, test bed [22], in particular metal [5] and orientation of the tags [23], were mentioned as important factors influencing the recognition rate of the RFID systems. According to that another set of experiments was designed to investigate performance of the RFID tag interacting with rebar cages. A complete block design with two replications was recognized appropriate. Number of rebar cages was selected as "blocks" while reader's orientation comprised the "treatments." A mixed model was developed for the ANOVA considering detection range as the response to the number of cages (fixed factor) and reader orientation (random factor). The tag, as shown in the Figure 10, was held on the geometric center of test plane. Measurements, in directions demonstrated in Figure 10, have been done by moving the reader from a farther distance towards the tag. The reader was set on "continues" mode meaning that tag would be detected automatically when it was in the range. Experiment set up was configured manually, therefore in order to assure that all readings were done in the same test environment data points could not be collected in random order. After first layer measurements have been done, the second layer of cages was added and readings were performed. Captured data is tabulated in Table 5. Statistically, replication makes study of interaction of factors possible. Therefore, interaction of factors was also included in the mixed model. In the second round of the experiments, when the top layer of cages was added, detection range in Direction \#3 fell below $90 \mathrm{~cm}$ that physically wasn't 
accessible. The measurement along Direction \#4 showed that if the reader got closer to the tag, it might detect it. But, as mentioned because of the size of the reader and design of the cage no measurement was recorded. Hence, Direction \#3 was excluded from the dataset used in ANOVA. P-value, the smallest level of significance that would lead to rejection of hypothesis of no effect, is used to extract importance of each factor. P-values for the test of the effect of block, treatment and interaction are $0.40,0.08$, and 0.00 respectively. P-value of 0.40 is not small enough to support rejection of null hypothesis implying that orientation of tag, doesn't affect detection range. The result implicates that the detection range is constant regardless of the angular position of the reader around the bare tag. In another word, the detection volume shapes a sphere around the tag. On the other hand, test on the effect of number of layers resulted on a statistics of $F=6.50$ corresponding to $\mathrm{P}$-value of 0.08 . Test statistic is fairly larger than 2 that provides enough evidence to conclude that increased number of layers decays detection range at significance level of $8 \%$. However, the most practical conclusion obtained from the ANOVA is the significance of the interaction of the factors. The statistic for the test on the interaction of factors is $\mathrm{F}=20.34$ which strongly indicates combined effect of the factors on detection range. This conclusion indicates that in real world applications when tags are randomly distributed in the concrete elements, the chance of being detected is not equal for all tags. In a simple word, a fraction of tags, are failed to be detected.

[Table 4]

[Table 5]

\section{Field-Testing of Prototype System}

Data about concrete mix design, raw material quality or used additives and admixtures can be included in a multi-aspect data repository embedded in the concrete element to be 
recalled during process execution, providing real time feed-back to participants, and future referring. In current practice, As soon as ready mixed concrete is emptied into the pump hopper, all mentioned information is lost. Furthermore, after drying, it can approximately be determined which part of the concrete element (slab, column, beam) corresponds to which truck load. Recorded in the data-base, it's an invaluable piece of information from the quality management point of view. If a sample does not pass the required quality thresholds, RF tags help to figure out roughly which part of the concrete object needs extra treatment.

Figure 11 pictures step by step experiments conducted at site. A $250 \mathrm{~mm}$ thick concrete slab at foundation level, designed as a substation holding special instrument, was targeted in an ongoing development project at UNSW. Based on the geometry of the slab (area: 950mmx770mm), three truck mixers were supposed to deliver required fresh concrete from the batch plant to the site. Each truck was equipped with a GPS box powered by the truck lighter. Figure 11-a) shows concrete foreman accessing real time position of delivery trucks screened on the $e$ CKisok. Figure 2 depicts a screenshot on the $e$ Kisok during the experiment. The interactive map provides information regarding the track's position as well as illustrative statistics of driver's performance. Beside the information provided by the GPS logistics agent, temperature data collected from the process was also available at real time. In order to test the survivability and performance of RFID tags as data carriers, embedded in the building elements, two tags were thrown in the hopper of the concrete pump at the beginning and at the end of unloading process of each truck. The identical code of each tag and the associated truck number were recorded by the concrete monitoring agent. Other sorts of information about mix design, raw material sources, time, date and weather condition can either be pre-stored on the chips or be linked to the tag's identity number on the central database. Photos of incomplete slab taken when a full truck replaced the empty one were used to manually determine area covered by each truck load. Three different areas corresponding 
to three trucks are presented in Figure 11-b). A month later, a centimeter precision Differential-GPS (DGPS) united with the RFID reader was utilized to scan the hardened slab in order to find and then accurately locate embedded tags. Collected position data as well as outcome of quality tests fed to construction quality agent to be recorded on the BIM files. As shown in Figure 11-c), the RFID reader not only powered the DGPS unit manufactured by ublox but also provided required processing capacity to interpret signals received from the GPS satellites. In total four out of six tags were successfully identified on the positions demonstrated in Figure 11-b). However, the first lesson learned is that to acquire a reliable distribution map, more tags per truck is needed associated to higher cost. In an interview with operation manager of the concrete supplier, the desirable incurred cost to deploy the system indicated to be less than 50 cents per tag. The current tags used in this study cost 2.70 USD each. But, the diving trend in market price of RFID tags promises widespread adoption of RFID technology in concrete quality management.

\section{Summary and Conclusion}

Lack of pervasive communication and interoperability of software are major obstacles to improve productivity, safety and quality in the construction industry. This paper presents a site-covering network model designed to add crucial new information channels to link the project network with the work-front. The ASCNet relies on electronic transmission or e-links to provide smooth and reliable data exchanges to a wide range of information nodes on- and off-site. This system enables in-process data acquisition for storage or analysis by software agents offering near-real-time progress updates. The "central gate" is a novel electronic data hub called the $e$ CKiosk. This dynamic and mobile center is equipped with various human interface capabilities, such as a large touch-screen, enabling construction personnel to retrieve up-to-date design drawings the location of approaching supply trucks, relevant safety 
rules, etc. directly at the work-front. At the same time, the hub is connected wirelessly to electronic sensors. Because ASCNet depends on reliable $e$-links among network nodes, the impact of construction activities on the quality of the electromagnetic signals was studied for both, short and long range applications. Measurements across a test-site provided the data to map signal behavior on a macro scale. Preliminary tests with WiFi enabled devices verified the efficacy of the ASCNet model and allowed the assessment of its reliability to serve as a communication platform. However, the results also confirmed the importance of considering the principles of electromagnetic attenuation since constantly shifting operations, equipment movements, material transports and changing surface contours impact the reliability of signals. The initial tests on long range signal propagation was extended to examine the performance of ZigBee, a wireless protocol to communicate data captured by electronic sensors. As hypothesized, the electronic emissions from construction equipment and radios interfere with ZigBee signals further emphasizing the risks of a dense WSN prone to signal jamming and the need for further investigations.

The meso-range tests with RFID tags embedded into concrete simulated the scenario where tags are thrown into truck mixer drums at the batching plant from where it is hauled, pumped and spread onto the formwork or poured into a wall form. Embedded tags showed sufficient readability ranges to be found by the RFID reader convert ordinary structural sections into active data sources linking them to the truck that delivered it and the batch number. Results from laboratory tests proved how the metallic "cage" structure may drastically reduce detectibly of tags, emphasizing the need for redundant tags.

In summary, the presented field tests provided a large data set processed to improve our knowledge about reliability and interoperability of eminent communication protocols available to create a wireless backbone for a site-based network such as the ASCNet. A longitudinal study is needed to assess the agility and value added performance of the eCKiosk 
supported by a ubiquitous wireless networks able to transmit electronic signals to and from the work front.

\section{References}

[1] E.W.L. Cheng, H. Li, P.E.D. Love, Z. Irani, Network communication in the construction industry, Int. J. Corp. Commun. 6 (2001) 51-70.

[2] A. Grilo, R. Jardim-Goncalves, Value proposition of interoperability on BIM and collaborative working environments, Automat. Constr. 19 (2010) 522-530.

[3] S. Nuntasunti, L. Bernold, Experimental assessment of wireless construction technologies, J. Constr. Eng. Manage. 132 (2006) 1009-1018.

[4] http://www.alfis.lv/uploaded_files/catalogue_files/HS843HD_data_sheet.pdf

[5] Ch. Tzeng, Y. Chiang, Ch. Chiang, Ch. Lai, Combination of radio frequency identification (RFID) and field verification test of interior decorating materials, Automat. Constr. 18 (2008) 16-23.

[6] D. Lupiana, C. O'driscoll, F. mtenzi, Defining smart space in the context of ubiquitous computing, UbiCC Journal Special issue on ICT Conference - Web and Agent Systems 4 (2009) 517-524.

[7] L.E. Bernold, S. AbouRizk, Managing Performance in Construction, first ed. , Wiley, New Jersey, 2010.

[8] P.R. Zekavat, M.M. Mortaheb, S. Han, L.E. Bernold, Comparative Study of GPS-Integrated Concrete Supply Management Using Discrete Event Simulation, J. Cons. Eng. Proj. Manag. In press (2014).

[9] J.Y. Ruwanpura, K.N. Hewage, L.P. Silve, Evolution of i-booth onsite information management kiosk, Automat. Constr. 21 (2011) 52-63.

[10] A. Dong, M.L. Maher, M.J. Kim, N. Gu, N., X. Wang, Construction defect management using a telematic digital workbench, Automat. Constr. 18 (2009), 814-824.

[11] K.N. Hewage, J.Y. Ruwanpura. A novel solution for construction on-site communication-the information booth. Canadian Journal of Civil Engineering. 36 (2009) 659-671.

[12] Dzeng, R. J., Fang, Y. C., \& Chen, I. A feasibility study of using smartphone built-in accelerometers to detect fall portents. Automat. Constr. 38 (2014) 74-86.

[13] C. Kim, T. Park, H. Lim, H. Kim, On-site construction management using mobile computing technology. Automat. Constr. 35 (2013) 415-423.

[14] L. Jaeseok, L.E. Bernold, Ubiquitous agent-based communication in construction, J. Comput. Civil Eng. 22 (2008) 31-39.

[15] R. Cole, A model for security in distributed systems, Comput. Secur. 9 (1990) 319-30.

[16] A. Dong, M.L. Maher, M.J. Kim, N. Gu, X. Wang, Construction defect management using a telemetric digital workbench, Automat. Constr. 18 (2009) 814-824.

[17] A.G. Arnold, Radio wave propagation and prediction in wildfires, $\mathrm{PhD}$ thesis, Texas A\&M University, Townsville, USA, 2008.

[18] M. Ward, R. van Kranenburg, 'RFID: Frequency, standards, adoption and innovation', JISC Technology and Standards Watch, May 2006.

[19] W.S. Jang, D.E. Lee, J.H. Choi, Ad-hoc performance of wireless sensor network for large scale civil and construction engineering applications, Automat. Constr. 26 (2012) 32-45. 
[20] Y.L. Samuel, H.P. Tserng, J.C.Wang, S.C. Tsai, Developing a precast production management system using RFID technology, Automat. Constr. 18 (2009) 677-691.

[21] L.Ch. Wang, Enhancing construction quality inspection and management using RFID technology, Automat. Constr. 17 (2008) 467-479.

[22] D. Grau, Z. Lei, X. Yang, Automatically tracking engineered components through shipping and receiving processes with passive identification technologies, Automat. Constr. 28 (2012) 36-44.

[23] S. Li, N., Li, G. Calis, B.B. Gerber, Impact of Ambient Temperature, Tag/Antenna Orientation and Distance on the Performance of Radio Frequency Identification in Construction Industry, In Computing in Civil Engineering (2011) 85-93. 


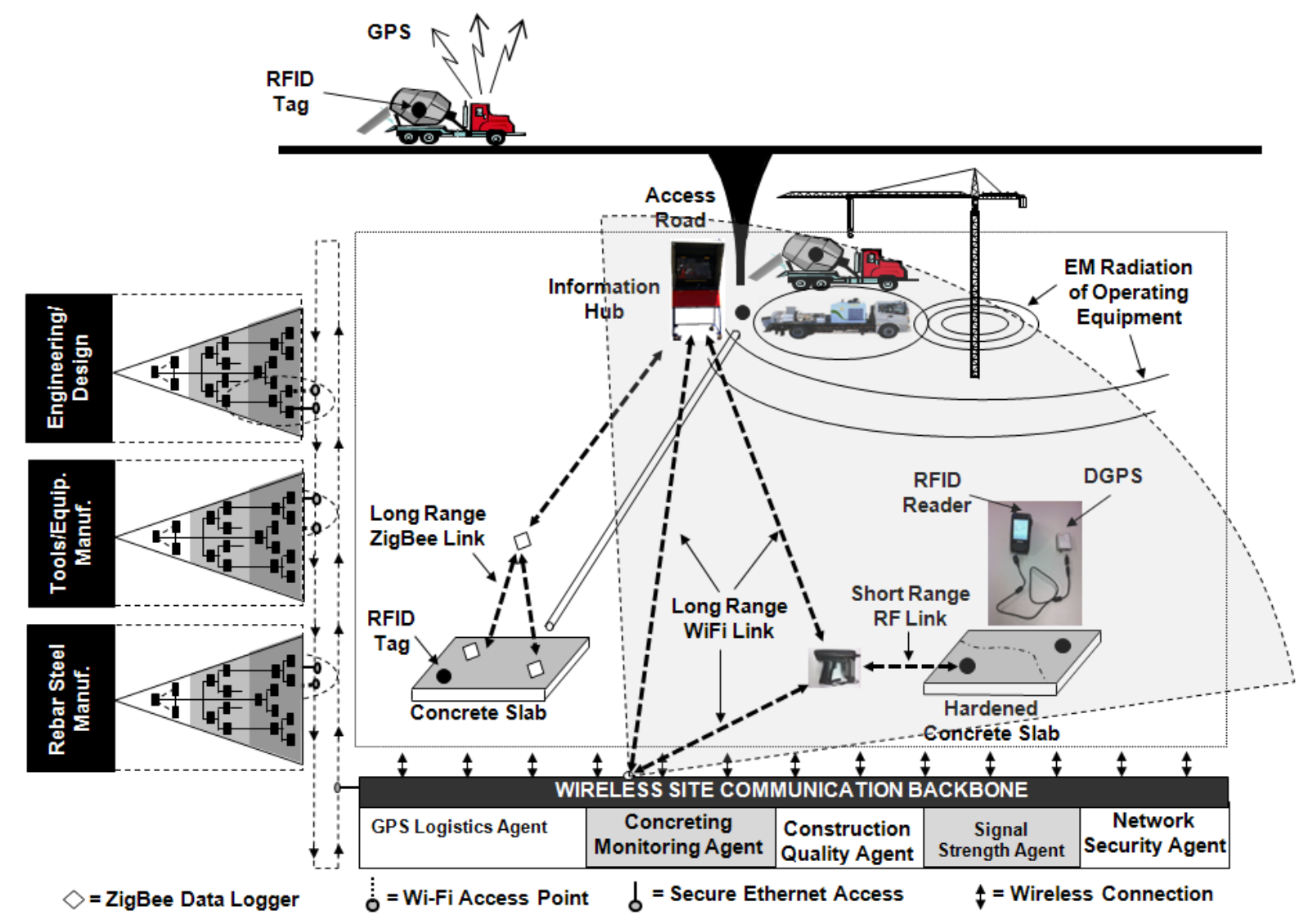

Fig. 1. Agile Information network for construction 


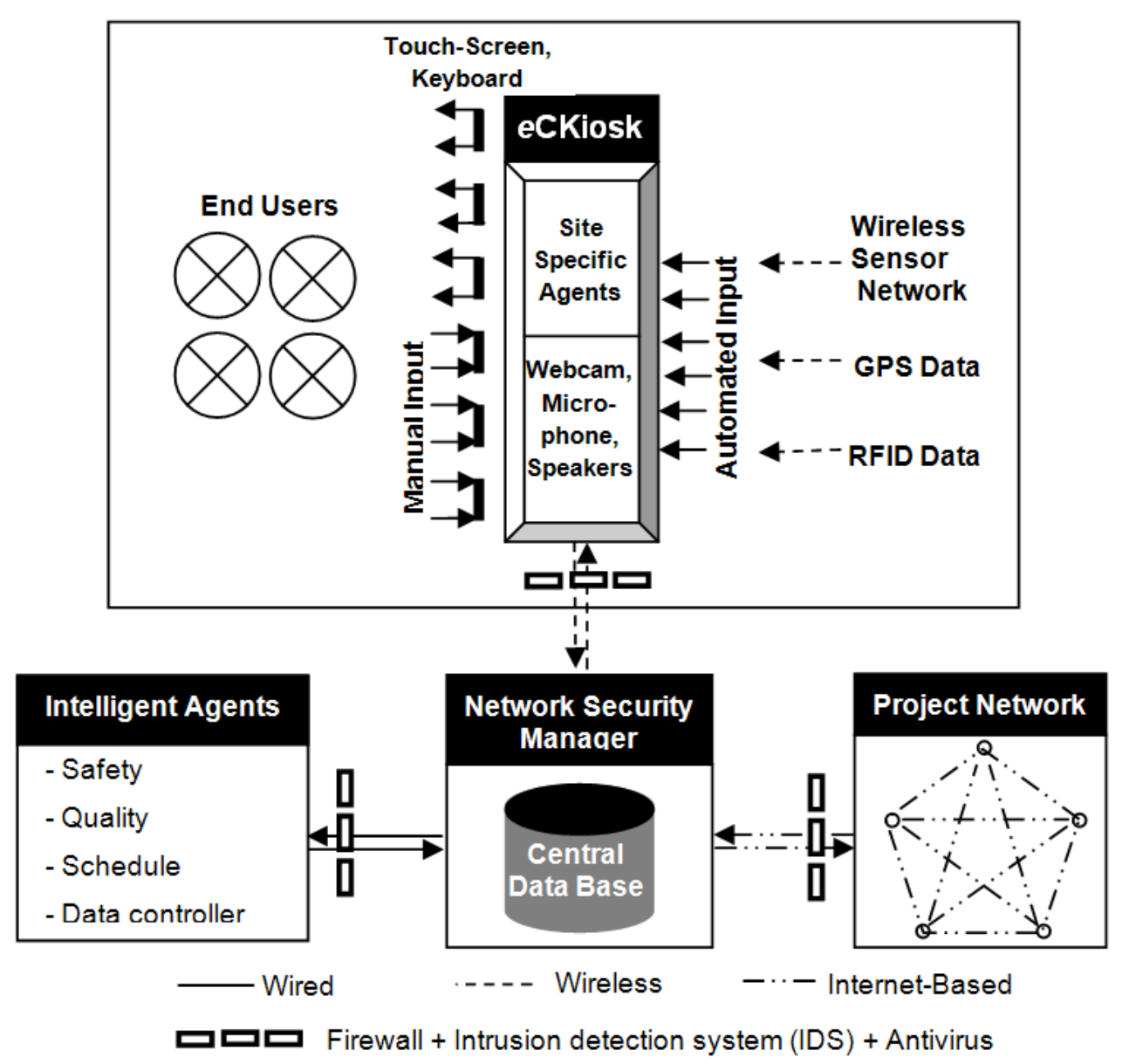

Fig.2. Architecture of Mobile Communication Hub 


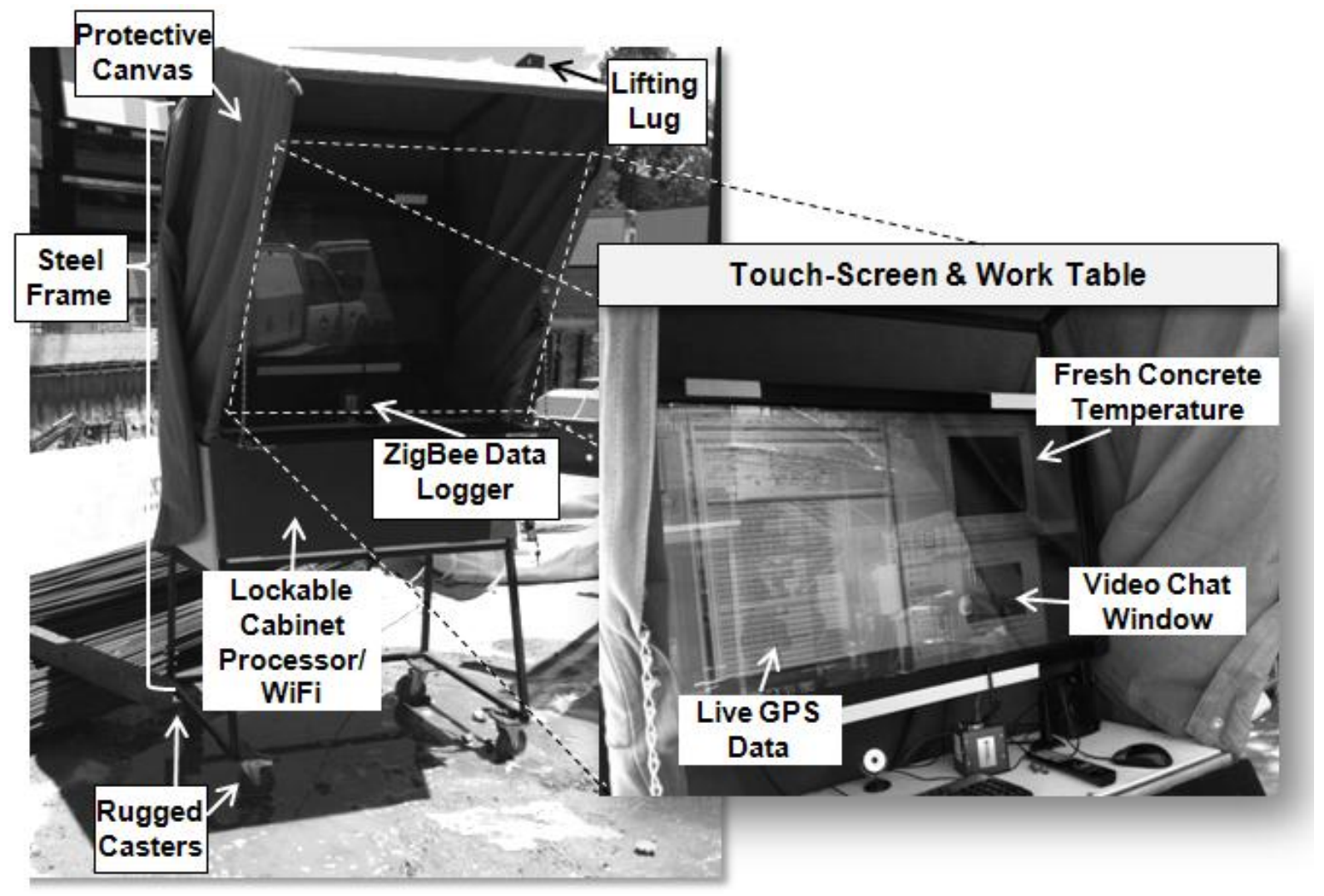

Fig.3. The mobile $e$ CKiosk prototype crane-lifted to the work-front 


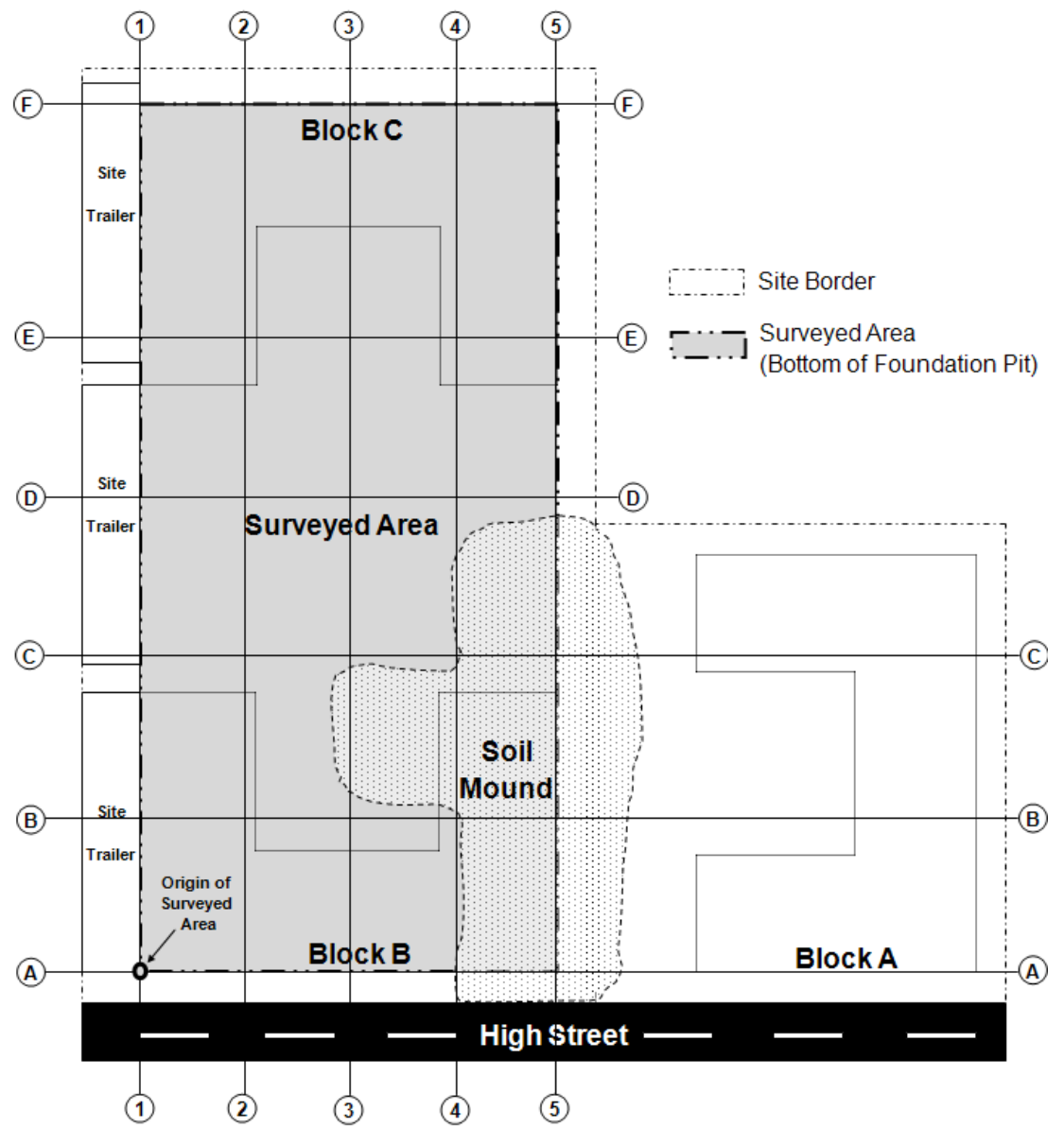

Fig. 4. Site plan and surveyed area at foundation level 


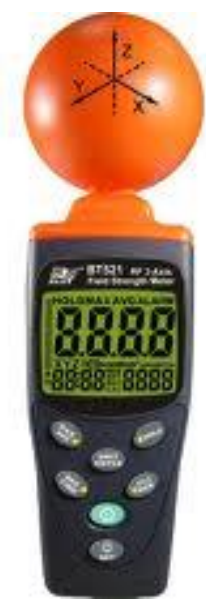

Figure 5. 3-Axis RF Field Strength Meter 


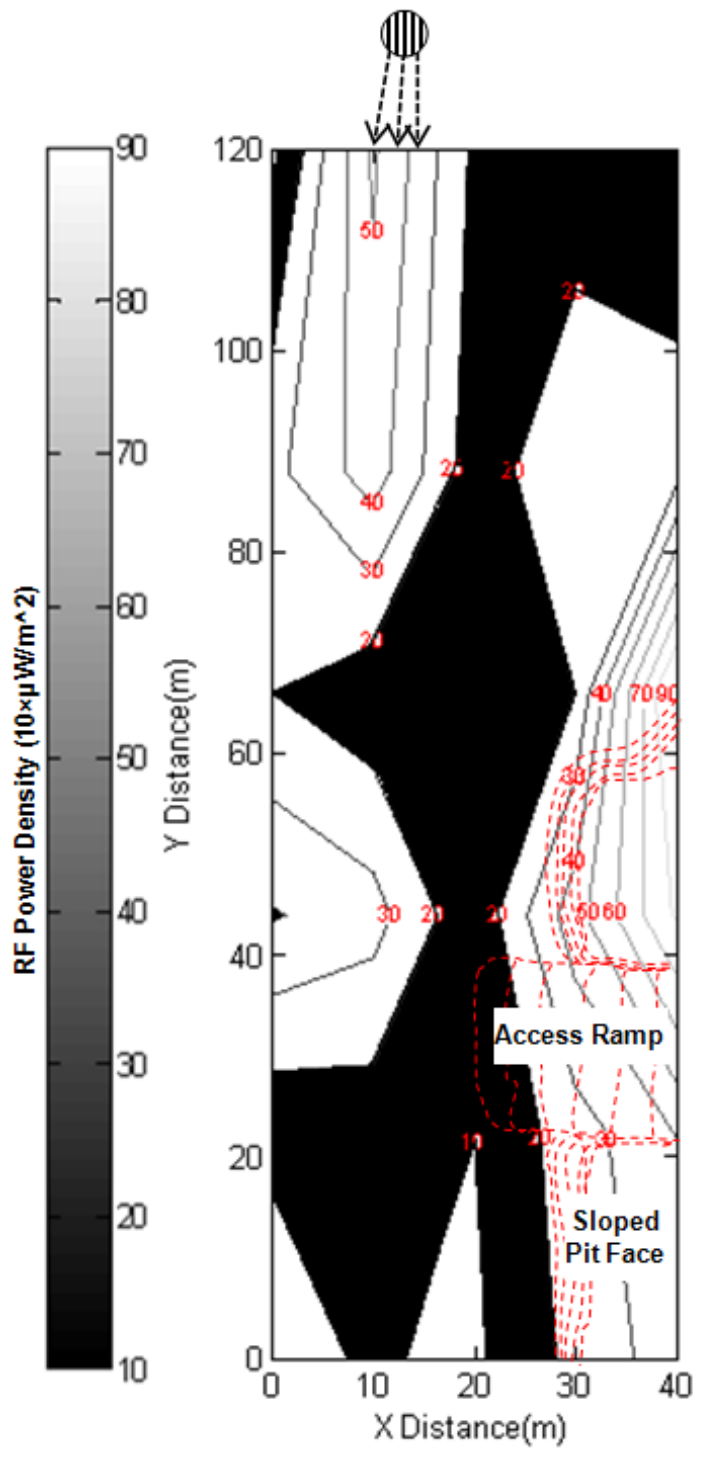

a) Basic signal propagation pattern 01/09/2012

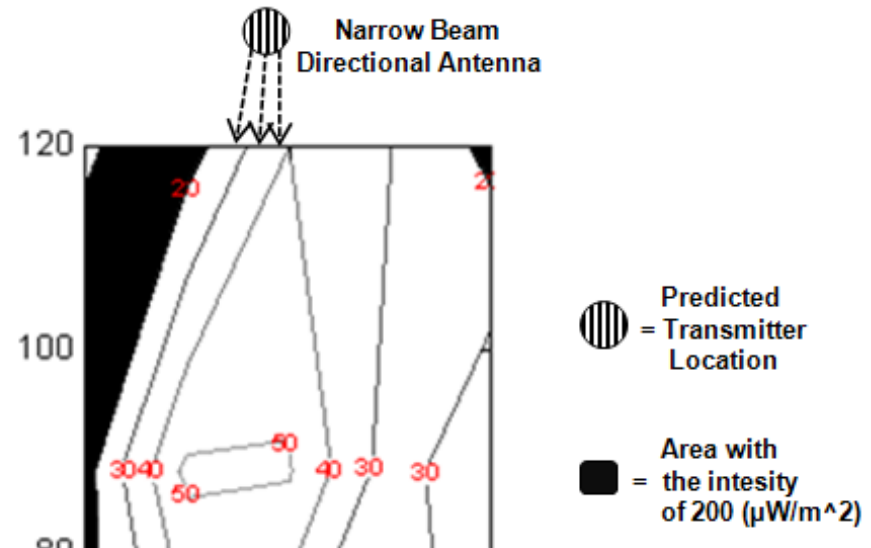

20

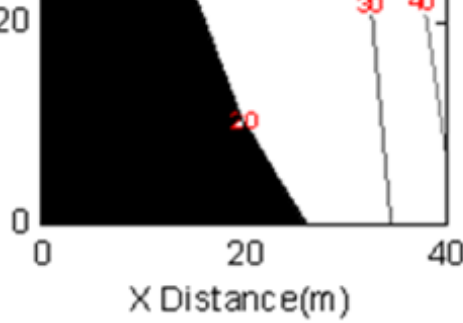

b) Soil removed on 24/09/2012

Fig.6. Measured signal propagation on site 


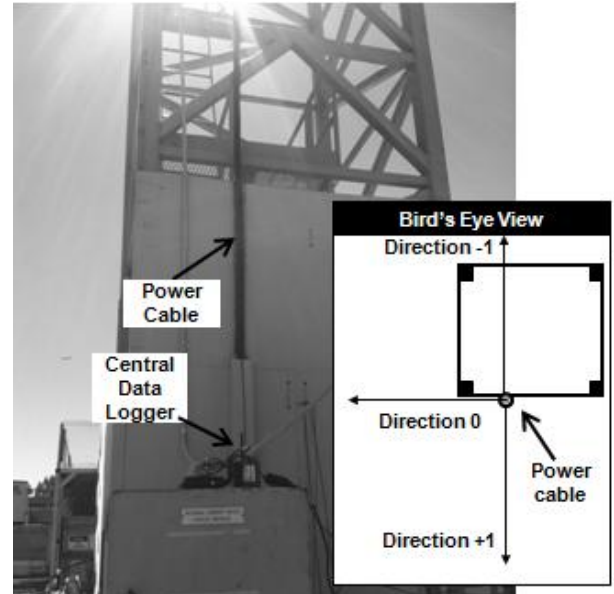

a) Power cable on the outside of the truss section

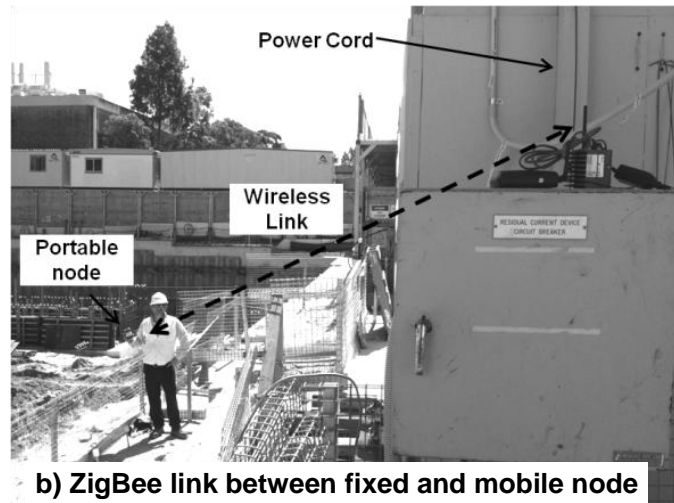

Figure 7. Experimental set up to measure crane's effect 


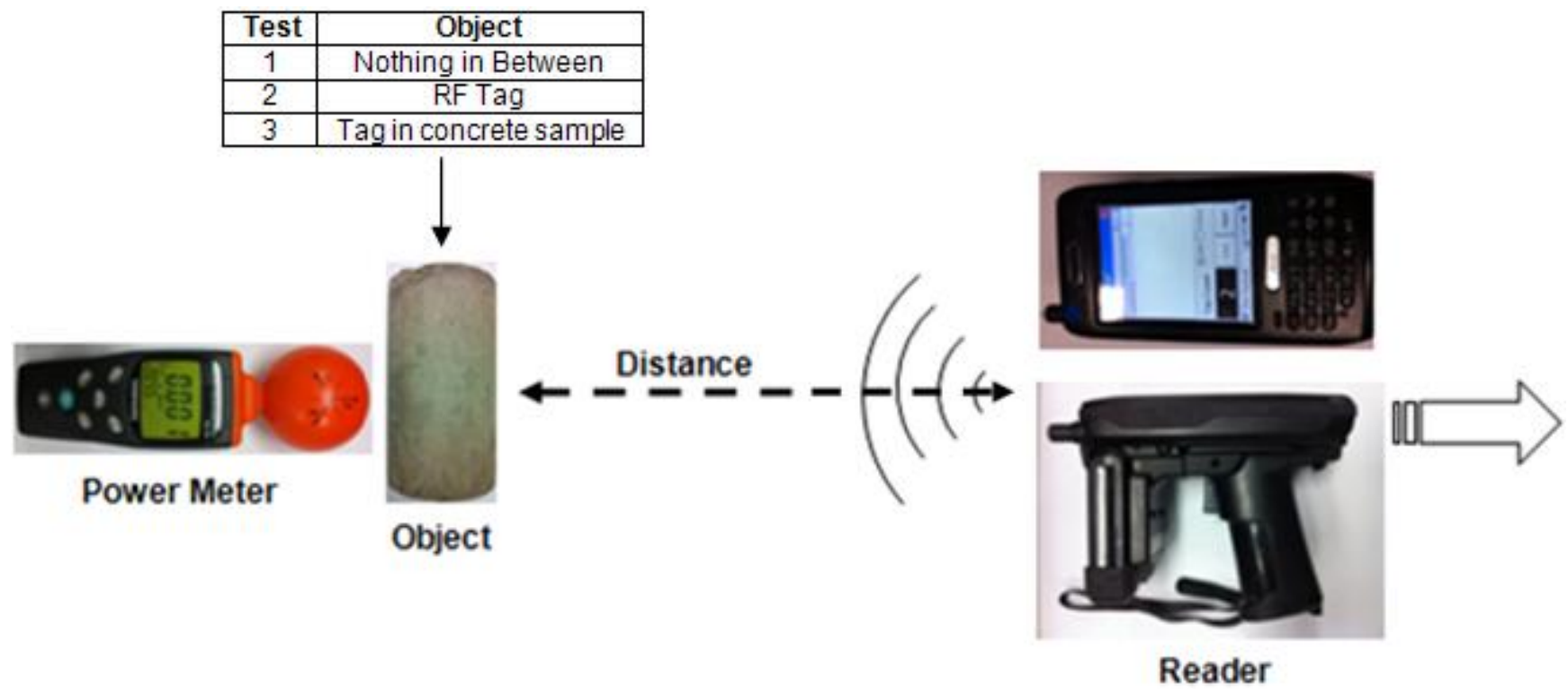

Fig.8. Experiment setup to measure effect of concrete on RF link strength 


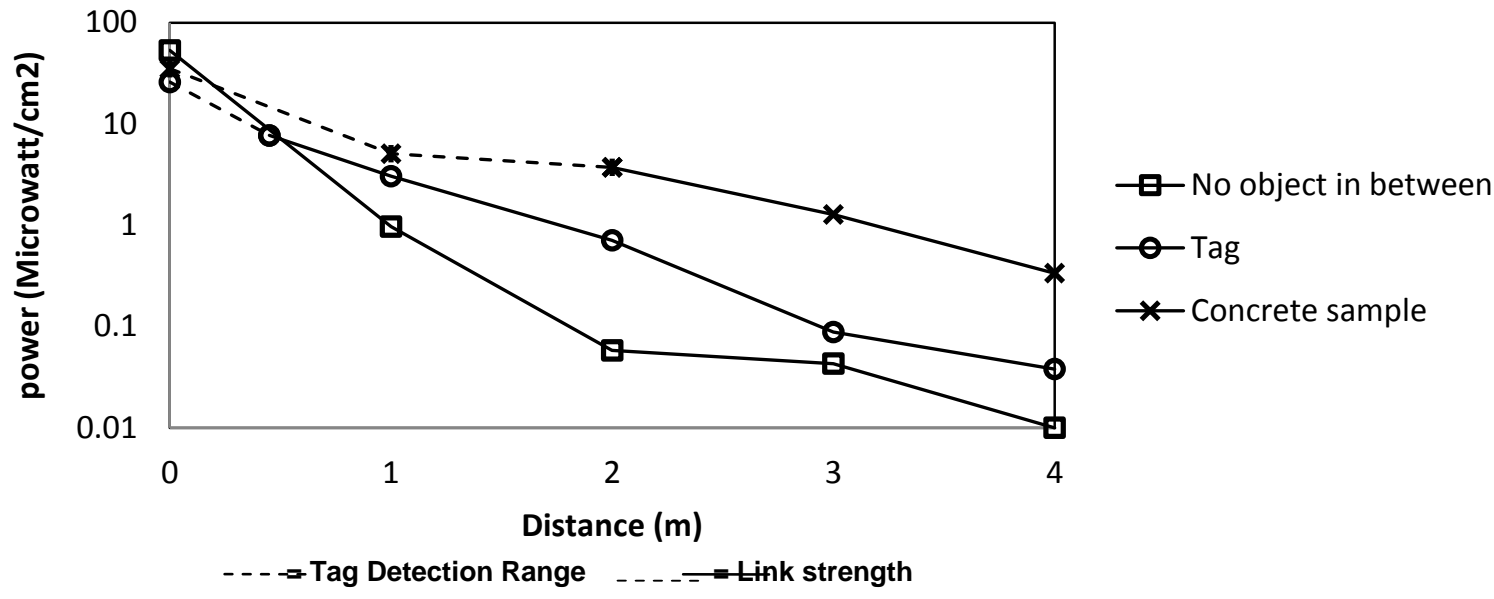

Fig. 9. RFID readability range results. 

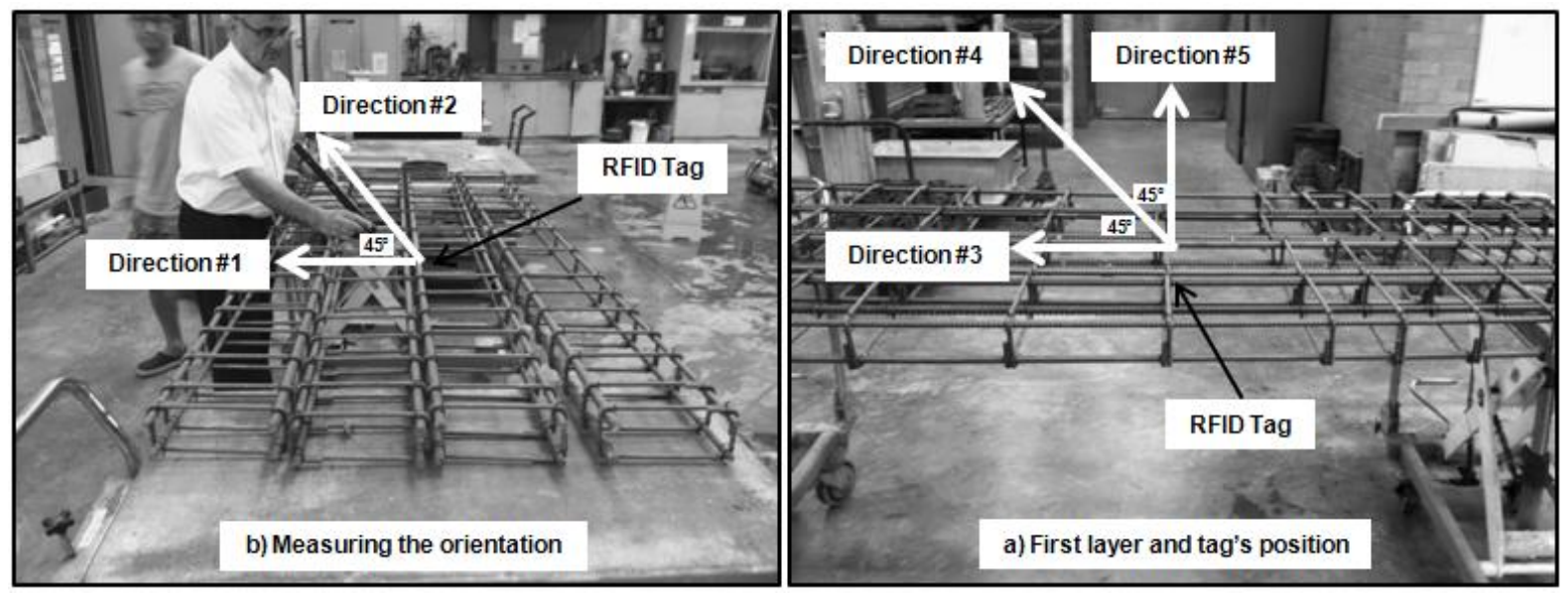

Fig. 10. Experiment setup to measure effect of rebar on detection range of the tags 

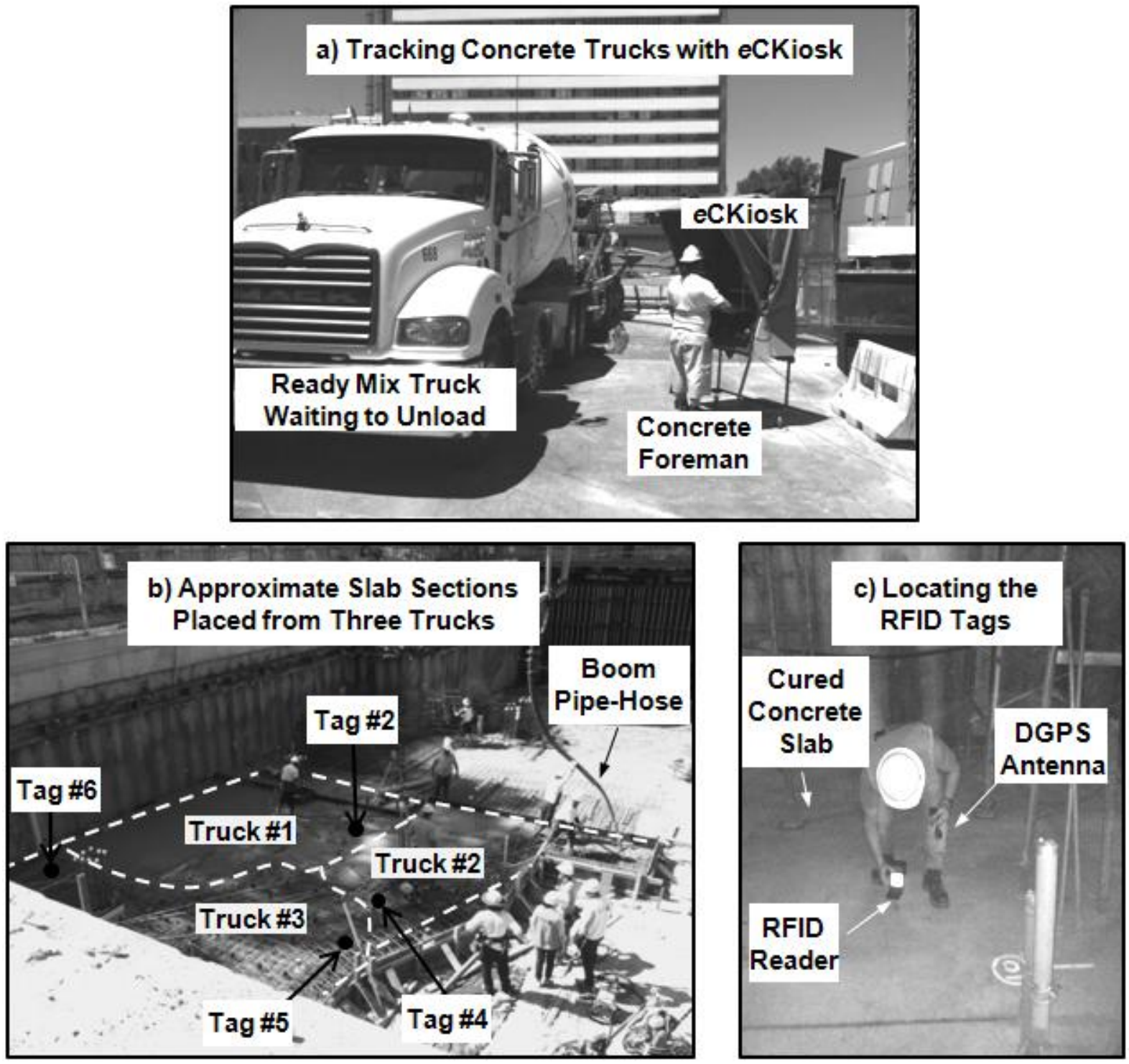

Fig. 11. Instrumentation and results of RFID embedded concreting 
Table 1. Average absorption values for various building materials

\section{Material}

Hollow wooden door

Hollow plasterboard/drywall

Brick/block wall, marble cladding

Double pane coated glass window

Reinforced concrete wall

Glass, tinted
Thickness

$4.5 \mathrm{~cm}$

$15 \mathrm{~cm}$

$7.5 \mathrm{~cm}$

$2.5 \mathrm{~cm}$

$25 \mathrm{~cm}$

N/A

\section{Loss (dB)}

4

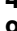

5-8

13

16

21 
Table 2. Data captured in order to investigate crane's effect on SQI

\begin{tabular}{|c|c|c|c|c|c|c|c|}
\hline \multicolumn{8}{|c|}{ Readings (Link Quality Index) } \\
\hline & \multirow{2}{*}{$\begin{array}{c}\text { Direction } \\
\text { Crane Status }\end{array}$} & \multicolumn{2}{|c|}{-1} & \multicolumn{2}{|c|}{0} & \multicolumn{2}{|c|}{+1} \\
\hline & & Active (+1) & Idle (-1) & Active (+1) & Idle (-1) & Active (+1) & Idle (-1) \\
\hline \multirow{6}{*}{ 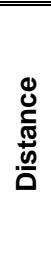 } & & $65^{(6)}$ & $72^{(16)}$ & $84^{(22)}$ & $58^{(5)}$ & $68^{(10)}$ & $79^{(31)}$ \\
\hline & $1 \mathrm{~m}(-1)$ & $78^{(15)}$ & $51^{(8)}$ & $66^{(3)}$ & $76^{(24)}$ & $86^{(26)}$ & $54^{(33)}$ \\
\hline & & $73^{(7)}$ & $78^{(2)}$ & $76^{(27)}$ & $62^{(9)}$ & $73^{(17)}$ & $53^{(14)}$ \\
\hline & & $56^{(36)}$ & $70^{(4)}$ & $78^{(21)}$ & $54^{(28)}$ & $78^{(19)}$ & $68^{(23)}$ \\
\hline & $5 \mathrm{~m}(+1)$ & $64^{(32)}$ & $44^{(1)}$ & $86^{(11)}$ & $70^{(13)}$ & $72^{(20)}$ & $84^{(35)}$ \\
\hline & & $59^{(18)}$ & $64^{(34)}$ & $76^{(30)}$ & $86^{(25)}$ & $71^{(12)}$ & $72^{(29)}$ \\
\hline
\end{tabular}

Superscripts indicate the random order of each run 
Table 3. Data captured in pairs to refine effect of using two-way radios during crane lift

\begin{tabular}{|c|c|c|c|c|c|c|c|c|c|c|c|c|c|c|c|c|c|c|c|c|c|c|c|}
\hline \multirow[b]{2}{*}{$\begin{array}{l}\text { Measurement } \\
\text { Number }\end{array}$} & \multicolumn{23}{|c|}{ Readings (Link Quality Index) } \\
\hline & 1 & 2 & 3 & 4 & 5 & 6 & 7 & 8 & 9 & 10 & 11 & 12 & 13 & 14 & 15 & 16 & 17 & 18 & 19 & 20 & 21 & Mean & $\begin{array}{l}\text { Standard } \\
\text { Deviation }\end{array}$ \\
\hline Radio Not In-Use $\left(X_{1}\right)$ & 73 & 72 & 66 & 72 & 61 & 76 & 68 & 56 & 86 & 71 & 76 & 59 & 84 & 86 & 67 & 62 & 76 & 78 & 78 & 86 & 78 & 72.9 & 8.9 \\
\hline Radio In-Use $\left(X_{2}\right)$ & 53 & 56 & 76 & 84 & 56 & 86 & 79 & 68 & 70 & 72 & 62 & 47 & 58 & 54 & 53 & 45 & 86 & 54 & 68 & 70 & 54 & 64.3 & 12.8 \\
\hline$D=X_{1}-X_{2}$ & 20 & 16 & -10 & -12 & 5 & -10 & -11 & -12 & 16 & -1 & 14 & 12 & 26 & 32 & 214 & 17 & -10 & 24 & 10 & 16 & 24 & 8.6 & 14.4 \\
\hline
\end{tabular}


Table 4. Data used to evaluate the effect of concrete on detection range

\begin{tabular}{|c|c|c|c|c|c|c|c|c|c|c|c|c|}
\hline \multirow[b]{2}{*}{$\begin{array}{l}\text { Measurement } \\
\text { Number } \\
\end{array}$} & \multicolumn{12}{|c|}{ Maximum Detection Range (m) } \\
\hline & 1 & 2 & 3 & 4 & 5 & 6 & 7 & 8 & 9 & 10 & Mean & $\begin{array}{l}\text { Standard } \\
\text { Deviation }\end{array}$ \\
\hline Bare Tag & $0.46^{(15)}$ & $0.53^{(6)}$ & $0.48^{(18)}$ & $0.67^{(11)}$ & $0.49^{(9)}$ & $0.47^{(7)}$ & $0.43^{(4)}$ & $0.59^{(14)}$ & $0.50^{(5)}$ & $0.39^{(17)}$ & 0.50 & 0.08 \\
\hline Concrete Cylinder & $2.09^{(3)}$ & $1.84^{(20)}$ & $1.77^{(16)}$ & $2.22^{(8)}$ & $2.02^{(19)}$ & $1.93^{(2)}$ & $1.99^{(12)}$ & $1.74^{(13)}$ & $2.29^{(10)}$ & $1.71^{(1)}$ & 1.96 & 0.20 \\
\hline
\end{tabular}

Superscripted number is the random order of collecting data 
Table 5. Data used to evaluate interaction of tag with rebar

\begin{tabular}{|c|c|c|c|}
\hline \multicolumn{4}{|c|}{ Maximum Detection Range (m) } \\
\hline \multirow{2}{*}{\multicolumn{2}{|c|}{ Blocks }} & \multicolumn{2}{|c|}{ Number of Layers } \\
\hline & & One & Two \\
\hline \multirow{10}{*}{ 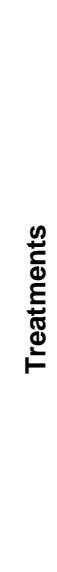 } & Direction & 0.82 & 0.60 \\
\hline & $\# 1$ & 0.75 & 0.85 \\
\hline & Direction & 1.24 & 0.70 \\
\hline & \#2 & 1.20 & 0.75 \\
\hline & Direction & 1.00 & N/A \\
\hline & \#3 & 1.40 & N/A \\
\hline & Direction & 0.60 & 0.14 \\
\hline & \#4 & 0.70 & 0.06 \\
\hline & Direction & 1.00 & 0.00 \\
\hline & \#5 & 1.25 & 0.00 \\
\hline
\end{tabular}

